\title{
El arbitramento como herramienta eficaz para la solución de conflictos en Colombia
}

\section{Arbitration as an effective tool for conflict resolution in Colombia}

\author{
DOI: https://doi.org/10.17981/juridcuc.18.1.2022.01
}

Fecha de Recepción: 2020/12/18 Fecha de Aceptación: 2021/06/12

\author{
Berónica Narváez Mercado \\ Corporación Universitaria del Caribe CECAR. Sincelejo (Colombia) \\ beronica.narvaez@cecar.edu.co \\ Fredy Castilla Paba \\ Corporación Universitaria del Caribe CECAR. Sincelejo (Colombia) \\ fredy.castillap@cecar.edu.co
}

Para citar este artículo:

Narváez, B. y Castila, F. (2022). El arbitramento como herramienta eficaz para la solución de conflictos en Colombia. Jurídicas CUC, 18(1), 9-34. DOI: http://dx.doi.org/10.17981/juridcuc.18.1.2022.01

Resumen

En artículo se enfocó en el Arbitramento en Colombia, desde la perspectiva de su relevancia en las diferentes esferas del Derecho Colombiano, no obstante; pese a considerarse una de las maneras más antiguas para resolver controversias entre las personas, es aún desconocida, dudándose entonces sobre su eficacia en la justicia privada que se imparte en los diferentes conflictos contractuales suscritos tanto por entidades públicas como privadas, germinando como problema de investigación, justificándose en la búsqueda de respuestas en la necesidad de dejar en claro la utilidad que posee el arbitramento en nuestro Estado, en donde se diseño como objetivo general el analizar la eficacia del arbitraje como herramienta para la solución de conflictos en Colombia; obteniéndose resultados a través de tres objetivos específicos al conceptualizar del arbitramento, identificar los asuntos sometidos a arbitraje en Colombia y establecer la eficacia del Arbitramento en Colombia; esto a través de un enfoque cualitativo bajo una metodología de estudio de casos, en una investigación jurídico dogmática, desde una perspectiva analítica, interpretativa o crítica del autor, concluyéndose que en la actualidad el arbitraje es eficiente como herramienta para la solución de conflictos en Colombia. Palabras clave: Arbitramento; cláusula compromisoria; tribunal arbitral; mecanismo alternativo de solución de conflictos; heterocomposición y eficacia

\section{Abstract}

This article focused on the Arbitration in Colombia, from the perspective of its relevance in the different spheres of Colombian Law, however, despite being considered one of the oldest ways to resolve disputes between individuals, it is still unknown; Despite being considered one of the oldest ways to resolve disputes between people, it is still unknown, doubting then about its effectiveness in private justice that is imparted in the various contractual disputes entered into by both public and private entities, germinating as a research problem, justified in the search for answers in the need to make clear the usefulness of arbitration in our State, where the general objective was designed to analyze the effectiveness of arbitration as a tool for conflict resolution in Colombia; The results were obtained through three specific objectives to conceptualize arbitration, identify the matters submitted to arbitration in Colombia and establish the effectiveness of arbitration in Colombia; this through a qualitative approach under a case study methodology, in a legal dogmatic research, from an analytical, interpretative or critical perspective of the author, concluding that arbitration is currently efficient as a tool for conflict resolution in Colombia.

Keywords: Arbitration; arbitration clause; arbitral tribunal; alternative dispute resolution mechanism; heterocomposition and effectiveness 


\section{INTRODUCCIÓN}

La gran demanda de procesos judiciales en Colombia, ha traído como consecuencia la búsqueda de nuevas herramientas que puedan suplir y superar a la Justicia Ordinaria, luego quienes acuden ante las distintas jurisdicciones se ven expuestos a que la solución de su conflicto tarde años, y posiblemente los recursos que deban obtener como producto de ellos resulten insuficientes ante el descuento de los gastos que tuvieron que sufragar para lograrlo, el tiempo que esperaron, los abogados que contrataron $y$, hasta recursos que invirtieron o en el peor de los casos prestaron. Entonces, con el fin de descongestionar la justicia fue que nacieron los Mecanismos Alternos de Solución de Conflictos, brindando apoyo antes y, después de la acción legal, encontrándose en su naturaleza compuestos por varias modalidades y, presupuestos dependiendo de cada asunto a resolver en particular, entre ellos tenemos la conciliación, la amigable composición, la mediación y el arbitramento; este último ha sido el más eficiente hasta la fecha.

No obstante; se ha generado una problemática en torno al desconocimiento que existe sobre la figura del arbitraje, y esto se debe a que además de nueva, es utilizada regularmente sólo por quienes poseen ingresos económicos suficientes como por ejemplo los empresarios, quienes en la mayoría de asuntos someten contratos a cláusulas que obligan a que sea un tribunal de arbitramento quien decida, lo mismo sucede tratándose de acuerdos estatales en los cuales surge la necesidad de resolver dichas controversias $\mathrm{y}$, pues se involucran sumas cuantiosas sobre el mismo lo cual desemboca en que el campo de atención en realidad este algo reducido. Los cuestionamientos antes señalados, han servido para que se amplié más el ámbito de acción del arbitramento en nuestro país, buscando de esta manera una mayor visualización y reconocimiento lo cual es bueno desde el punto de vista de los avances que el estado social de derecho debe ir aplicando a las actuaciones de los diferentes actores del Estado, buscando lograr con ello, descongestión, agilidad y, eficiencia en las administraciones de 
justicia de cara a la verdad de las realidades que afronta un país que permanentemente vive sometido a reformas constitucionales y legales sea a través de demandas de inconstitucionalidad ante la Corte Constitucional, o proyectos de ley que se tramiten en el Congreso de la República de Colombia.

Por lo precedente y, ante la necesidad de medir la fuerza de este método de resolución de conflictos, se debe resolver la siguiente cuestión: ¿Es eficaz el arbitraje en Colombia? Pues, si bien se conoce su funcionamiento, es subvalorado por la comunidad, debido a las dificultades para acceder a él. Sin embargo, al no dejar de brillar sus beneficios, se busca como resolver el problema, por medio de un objetivo general, como es determinar la eficacia del arbitraje en Colombia. Este mismo se expondrá desglosando los objetivos específicos en su orden: (i) la conceptualización del arbitraje en Colombia; (ii) la identificación de los asuntos sometidos a arbitraje en Colombia y, (iii) el análisis de las razones de la eficacia del arbitraje en Colombia. Estos objetivos se indagarán utilizando un enfoque cualitativo mediante metodología de estudio de casos.

En Colombia el arbitraje data a partir de la Ley 105 de 1890, que facultaba a las personas para someter sus diferencias a la decisión de un árbitro, en ciertos casos pre establecidos por la ley y de acuerdo al procedimiento prescrito para tales situaciones (Narváez y Osorio, 2018, p. 1).

El presente artículo finaliza con el análisis de la eficacia de la figura del arbitramento en nuestro país, la cual fue impulsada en la Constitución Política de 1991, desarrollada de manera significativa y eficaz, aunque la mayoría de los asuntos son de altas cuantías, demostrando que la cantidad no siempre va acompañada de la calidad, pues una cosa es que solo sectores exclusivos la utilicen y otra, que no sea certera.

El artículo parte de una investigación jurídica, de tipo descriptivo, al conceptualizar los planteamientos generados, como son el arbitraje en Colombia, específicamente en materia de derecho civil y comercial, por tanto, se aplicará un enfoque cualitativo, 
resaltándose las particularidades menos notables de la figura de este arbitraje, aplicando un método lógico inductivo, a través de un examen de todas las figuras que confluyen como fundamentales para resolver el análisis de la eficacia del proceso arbitral en Colombia, desde una perspectiva analítica, interpretativa o crítica del autor. Como consecuencia del tipo de investigación, las fuentes utilizadas serán secundarias, luego se sustraen de leyes, doctrinas y jurisprudencia, las cuales una vez analizados se proferirán consideraciones en cuanto al tema.

La población estudiada se enfoca en la delimitación espacial como es Colombia, pues sólo se habla de arbitraje nacional, lo que involucra sólo a las personas que utilicen este mecanismo alterno de solución de conflictos.

Se toman como muestras las leyes de Mecanismos de Resolución de conflictos vigentes en Colombia, y el resultado se empleará en toda la comunidad nacional, que, en alguna oportunidad de su quehacer solicite la aplicación de un proceso arbitral.

Se utiliza como Instrumento de recolección de información el análisis de tipo documental en el cual se incluyen diferentes escritos relacionados con la materia del arbitraje, así como los distintos extractos jurisprudenciales encontrados.

\section{Discusión}

\section{Conceptualización del arbitraje en Colombia}

Para iniciar, según el Diccionario de la Real Academia de la Lengua Española-RAE la palabra conflicto tiene varias definiciones: "lo más recio de un combate, punto en que aparece incierto el resultado de la pelea, combate y angustia de ánimo, situación desgraciada y de difícil salida" (RAE, s.f). La palabra conflicto se deriva de la voz latina "confligere", que significa combatir y en un sentido amplio se entiende como tal, "controversia, antagonismo, desacuerdo" (Caicedo, Villalobos y Murgas, 2014, p. 13). Así, Alzate (2011) en su obra Teoría del conflicto, explica que el mismo es: 
Un mal necesario dentro de la sociedad, que en principio es tomado como negativo pero que puede transformarse a través de los mecanismos alternos de solución de conflictos, pero que primero se debe identificar que tipo de conflicto es si de relación, información, intereses, estructurales, y de valores (p. 1).

Por otra parte, Fuquen (2003) nos indica que los conflictos están motivados por factores de tipo social, con los cuales debemos aprender a convivir, utilizándolos de manera positiva en la relación con nuestra comunidad, para lo cual se han fijado diversas estrategias entre ellas las correspondientes al arbitraje. Así las cosas, se tiene que es necesario que el conflicto exista, para que pueda continuar el curso normal de su naturaleza, el cual dependerá de cada uno de nosotros, a través de su carácter y valores, el cual requiere en la mayoría de los casos ayuda de un tercero neutral. Al referirnos a estas personas capacitadas pero ajenas al conflicto que deben ayudarnos una vez les hemos encargado dicho propósito, tenemos entonces a continuación los diferentes mecanismos de solución de conflictos como son la conciliación, negociación, mediación, amigable composición y arbitraje, este último quien tendrá un título aparte y más extenso en razón al propósito de este trabajo.

\section{Mecanismos Alternos de Solución de Conflictos}

En primer lugar, se hablará de la conciliación, en cuanto a ella existe el Decreto 1818 (1998), a través del cual se creó el Estatuto de los Mecanismos Alternos de Solución de Conflictos, la cual empieza hablando de la conciliación judicial y extrajudicial: "La conciliación es un mecanismo de resolución de conflictos a través del cual, dos o más personas gestionan por sí mismas la solución de sus diferencias, con la ayuda de un tercero neutral y calificado, denominado conciliador" (1998, art. 1). Se desprende entonces que la conciliación surge de la necesidad de resolver conflictos a través o con apoyo en otra persona, sin embargo el que al final decida son quienes se encuentren involucrados, por tal motivo es fundamental tener claridad sobre la problemática que se llegare a plantear. 
Ahora, de igual manera el tratadista Gil (1989) define la conciliación como un mecanismo extrajudicial alterno de solución de conflictos, mediante el cual las partes buscan arreglar sus discrepancias con la colaboración de una tercera persona llamada mediador, también dijo en su recorrido histórico que, en un principio la conciliación no necesitaba de la existencia de normas que la regularan (CabanaGrajales, 2017).

Pero más adelante con el Decreto 2279 (1989, art. 49) se abrió campo a la misma, procediéndose posteriormente a la Ley 23 (1991) a través de la cual "se crearon los centros de conciliación en Colombia", regulándose en última instancia por la Ley 640 (2001) (Gil, 2011). En cuanto a la conciliación según Peláez (2017) es definida como un mecanismo de solución de conflictos, que otorga el Estado, para aquellas personas que no quieran extender más una discusión y que prefieren arreglar sus diferencias antes que acudir ante un juez. Respecto a las características de la conciliación, Junco (2007) expone:

Es el acuerdo logrado en razón a la comprensión y entendimiento amigable $\mathrm{y}$, voluntario de las partes dadas en conflicto, les ahorra dinero y tiempo a las personas involucradas y al aparato judicial, es informal pues se busca que las partes se entiendan cómodas y, dure el tiempo en el que ellos resuelvan la situación a gusto. Y también en algunas ocasiones es necesario su agotamiento para que las demandan sean aceptadas por el juez, el conciliador es una persona ajena al conflicto, por ello es solemne, bilateral, onerosa a excepción de aquella que se ofrece en los consultorios jurídicos de las facultades de derecho, conmutativa, pues las personas deben conocer el alcance del acuerdo, de libre discusión y nominada, pues debe quedar por escrito el acuerdo, no acuerdo al que se haya llegado (p. 1).

Así mismo, en la colección Breviarios Legislativos, sobre las reglas que deben contener las conciliaciones precedidas por un tercero neutral, son: "Equidad, Economía procesal, Celeridad, Oralidad, Persuasión racional, Preclusividad, confidencialidad" (Legislativos, 2001). De esta forma concluimos, que este mecanismo alterno es fundamental cuando las partes necesitan la asesoría de un experto 
para manejar sus diferencias, lo cual es relevante para la comunidad que se encuentra inmersa en conflictos que involucren no solo conceptos económicos sino aspectos especiales.

A continuación, nos encontramos en segundo lugar con el Mecanismo Alterno de Solución de Conflictos (MASC), denominado Negociación, el cual es definido como el hecho de llegar a un acuerdo a través del habla y, escucha entre las partes en conflicto, en donde los representantes de las partes o estas, son quienes discuten los intereses, siempre motivados en llegar a un certero acuerdo, obtenido beneficios mutuos siendo el objetivo ineludible (Manzano y Torres, 2000).

Las características de este MASC, consisten en la acentuación amigable de las partes interesadas de manera privada, para obtener lo que se quiere individualmente, pero al menor costo posible, confidencialidad entre las partes que intervienen y hacerlo de manera voluntaria, pero con conocimiento previo de quien es la otra persona y que es lo que en realidad desea, para así generar mejores propuestas (Montes, 2018).

Sumado a ello, Galicia (2016) habla de los principios que lo regulan como son: La equidad, principio de veracidad, principio de buena fe, principio de confidencialidad, principio de celeridad, principio de economía para las partes negociadoras, principio de honestidad, principio de imparcialidad y principio de honestidad. Así entonces, es claro que la negociación muestra una cara de escucha certera y recomendativa frente a las partes interesadas, y que en realidad son ellos mismos quienes determinan sus fórmulas de arreglo con fundamento en intereses.

Seguidamente, nos encontramos con el mecanismo alterno de la Mediación, como aquel que busca solucionar conflictos de manera pacífica, que explota la esfera interior del dolor humano, pues pese a que busca llegar a acuerdos, también tiene como finalidad sanar internamente a quienes intervienen y mantener una relación de armonía entre las partes, pues aquí no existe un tercero que pueda ser imparcial, sino que se llega a un entendimiento genuino (Pérez, 2015). 
Conservando la mediación las características de la voluntariedad, es decir, que nazca de manera espontánea de las partes arreglar sus diferencias; confidencialidad de todas las partes incluido el mediador, quienes jamás deberán divulgar lo escuchado en la conversación; la neutralidad e imparcialidad, como aquella que debe aportar a ambas partes del conflicto, en la misma proporción, sin inclinaciones de ningún tipo; la autorresponsabilidad de las partes, como aquellas que deciden si termina el asunto o si prefieren dejarlo inconcluso. Y por última característica, la flexibilidad, por cuanto el entorno en medio de la mediación es creado por las partes quien lo adaptan de acuerdo con lo buscado (Peláez, 2017). Regulándose la mediación bajo los principios de igualdad, libertad, bien común, oralidad, imparcialidad, justicia (Corporación Nuevo Arcoiris, 2003).

De lo expuesto se desprende que la mediación no es más que la necesidad de las personas por mejorar sus relaciones empezando por aceptar que debe ser de esa manera, bajo la espontaneidad necesaria para resolverse a través de una previa adaptación de las razones. Para finalizar sobre los MASC, tenemos la amigable composición, definida según la Ley 1563 (2012), como aquella en la cual

Dos o más particulares, un particular y una o más entidades públicas, o varias entidades públicas, o quien desempeñe funciones administrativas, delegan en un tercero, denominado amigable componedor, la facultad de definir, con fuerza vinculante para las partes, una controversia contractual de libre disposición (párr. 1)

Se tiene entonces, que este MASC es heterocompositivo luego quien en realidad resuelve al final las diferencias es una tercera persona, es también de carácter oneroso luego quienes sometieron a consideración de un tercero su conflicto deben pagar los honorarios por el desarrollo del mismo, es importante decir, que el amigable componedor podrá ser cualquier persona encargada previo consentimiento entre las partes, además la desición que se tome hara transito a cosa juzgada, lo cual no indica que necesariamente no es objeto de contradicciones. 
Los diferentes mecanismos han sido fuertemente utilizados, sin embargo; en mayor medida aquellos que no traen consigo el pago de honorarios por su gratuidad en diferentes sectores como en consultorios jurídicos y/o entidades del estado que de manera gratuita prestan estos servicios, remitiéndose la menor cantidad de casos a las Cámaras de Comercio de las diferentes ciudades, esto por el valor remunerativo que trae dicha prestación, por ello, es necesario tener en claro que tipo de metodo requerimos y/o que nos brinden asesoría al respecto.

\section{Fundamento Constitucional del Arbitraje en Colombia}

En sus inicios el arbitramento en Colombia, partió con la Ley 23 (1991) en donde se señaló de entrada que "este podría ser institucional, porque se llevaría a cabo a través de los centros de arbitramento" (art. 90), y también de manera independiente del que habla el Decreto 2279 (1989) derogado por la Ley 446 (1998, art. 167). El arbitraje institucional puede ser ejercido por las asociaciones, fundaciones, agremiaciones, corporaciones, así como Cámaras de Comercio, que tengan como mínimo 100 miembros y dos años de experiencia, los cuales podrían crear sus propios centros de Arbitraje, con la debida autorización del Ministerio de Justicia.

Por otra parte, el arbitramento independiente, hace referencia a que las partes directamente escojan a quienes integraran el arbitramento, confirmando un tribunal de su preferencia lo cual es innovador en tratándose de medios gratuitos, pero como este no lo es, existe la excepción. Así entonces, el arbitraje en Colombia, surgió como una herramienta para solucionar diferencias que nacierón de la celebración de un contrato, se observa aún más en conflictos generados entre comerciantes, empresarios, entre otros, personas que pueden ser tanto naturales como jurídicas, y requieren la intervención de un árbitro, pero "es fundamental que el contrato inicialmente celebrado entre los intervinientes, tenga una cláusula que habilite para arreglar las diferencias en el arbitraje, o si no lo hicieren manifestarlo por escrito" (Cifuentes, 2018). Según Gil (2011): 
El árbitro define el conflicto de manera autónoma, a través de un fallo denominado laudo arbitral, el conflicto sometido a arbitraje podría desaparecer en cualquier momento utilizándose la conciliación entre las partes que intervengan, las partes que conforman el tribunal pueden ser escogidas por las partes, es de carácter oneroso, pues quienes pretenden acceder al arbitramento deberán pagar los honorarios de los árbitros (p. 1).

Y los principios que regulan al arbitraje son la Imparcialidad, neutralidad, objetividad, Idoneidad, Oralidad, Igualdad y Contradicción (Cristóbal, 2013). Por su parte, la Ley 1818 (1998), además de contener al igual que las normas anteriores el arbitraje institucional y el independiente, nos desglosa el procedimiento al que se está sometido para llevarlo a cabo de manera fehaciente. Entonces, en primer lugar, se requiere de la existencia de un pacto arbitral, el cual indica que los contratos celebrados entre partes estarán sometidos a las denominadas cláusulas compromisorias y el compromiso, que nos ubica en que cualquier desacuerdo existente entre ellos se someterá ante un Tribunal de Arbitramento. Mientras la cláusula compromisoria, incorpora la obligación de resolver el conflicto a través de un Tribunal de Arbitramento, en un documento diferente al del contrato celebrado, y en el mismo momento, mientras que el compromiso, espera que el conflicto exista para poder surgir previo acuerdo de escogencia de dicha solución por las partes.

Los árbitros son aquellas personas que "integran el tribunal de arbitramento, nombrados por las partes o por la institución delegada para ello, el número de árbitros es de máximo tres, a excepción de la menor cuantía que sólo puede ser un árbitro" (García, 2013). Los árbitros están en la obligación de comunicar a quien los asigno, si aceptan o no el cargo dentro de los cinco días siguientes a la notificación, al conformarse el Tribunal se deberá escoger a un presidente y por ende un secretario, celebrándose la primera audiencia que es la de conciliación, y luego procediéndose a la audiencia de trámite, audiencia de pruebas y medidas cautelares, por último se profiere el laudo arbitral y queda la posibilidad de presentar recurso 
de anulación, de lo cual conocerá Tribunal Superior del Distrito Judicial, donde se haya agotado el arbitramento. "Este recurso debe presentarse dentro de los 5 días siguientes a la notificación del laudo arbitral a las partes, y en consecuencia puede hacerse para corregir, aclarar o complementar lo señalado en la decisión" (Cristancho, 2002). No obstante, es importante anotar que cuando se trate de laudos arbitrales, que hayan surgido en razón a conflictos que surjan de contratos estatales procederá el recurso de revisión contra el mismo.

Actualmente el arbitraje se rige por la Ley 1563 (2012), la cual se encuentra depositada en la Constitución Política de Colombia (CP, 1991, art. 116), lo cual derogó toda la normatividad precedida, hablándose entonces de los fallos en derecho y en equidad, además consagro lo siguiente:

En los arbitrajes en que no sea parte el Estado o alguna de sus entidades, los particulares podrán acordar las reglas de procedimiento a seguir, directamente o por referencia a las de un centro de arbitraje, respetando, en todo caso los principios constitucionales que integran el debido proceso, el derecho de defensa y la igualdad de las partes. En el evento en que las partes no establecieren reglas o el centro seleccionado para adelantar el trámite no tuviere reglamento de procedimientos debidamente aprobado, se aplicarán las reglas establecidas para cada caso en la presente ley (Art. 58).

De lo expuesto, se tiene que cuando sean entidades privadas o particulares los que invoquen a conformar el arbitramento puede escoger el procedimiento establecido, lo cual resulta algo contradictorio, toda vez que dependiendo del área en la cual se genere el conflicto, se encontraran normas especiales que regulen su procedimiento. No obstante, lo anterior, se tiene que a excepción de lo reseñado en la Ley 80 (1993), el trámite de arbitraje se resume actualmente en lo siguiente:

1. Solicitud de convocatoria de Tribunal de Arbitraje, a través de su respectiva acción ante la entidad que pretende le ayude en el asunto. 
2. Designación de árbitros por acuerdo entre las partes, de lo contrario lo hace el juez civil u ordinario.

3. Se nombra al presidente y su respectivo secretario.

4. Se consignan los respectivos honorarios proporcionalmente a la mitad por cada una de las partes convocantes.

5. Luego procesalmente se sigue con la admisión o no de la demanda, el respectivo traslado, y contestación para la otra parte contando con el término de ley para hacerlo como son los 10 días.

6. Citan a conciliación.

7. Audiencia de trámite, en donde queda al descubierto el porqué del conflicto, y se agotan los requisitos de procedibilidad correspondientes, fijándose la respectiva fecha para pruebas.

8. Se manifiestan los alegatos de conclusión.

9. Se dicta laudo arbitral el cual es equiparable a una sentencia.

10. Luego se puede dar la aclaración, complementación o adición del laudo arbitral, y posteriormente recurso de anulación, no obstante, con esta nueva norma del 2012, también se podrá presentar recurso de revisión y tutela (García, 2013).

Como nueva novedad, ahora el recurso de anulación no será de competencia del Tribunal del Distrito Judicial del respectivo Departamento, sino por el contario "a cargo de la Corte Suprema de Justicia en su Sala Civil, mientras que tratándose de conflictos en donde intervenga una entidad pública lo será el Consejo de Estado en su sección Tercera de lo Contencioso Administrativo" (García, 2013, p. 1). Así entonces, el arbitraje posee un tramite judicial, integrado por los arbitros que son los jueces en los casos que les atañen, además es formal, heterocompositiva pues requiere de ambas partes involucradas, tiene un fundamento constitucional, se finaliza o termina con el denonimado laudo arbitral que viene siendo la sentencia, además ejerce función pública, se le pagan honorarios a los arbitros, pero estos solo pueden ser personas jurídica, mas no naturales. 
Ahora, es fundamental indicar que siempre que se dé apertura a integrar el tribunal de arbitraje, "existirá la oportunidad de agotar la conciliación extrajudicial, según el inciso 3 del artículo 110 del Código General del Proceso, lo cual reitera el carácter juridicial que posee el arbitraje en Colombia" (Junco, 2007, p. 1). De igual manera, Narváez y Osorio (2018), al tratar el tema del arbitraje en Colombia fueron enfáticas en manifestar que el arbitraje es una figura transitoria, y que en realidad se trata de un proceso judicial que complementa a otro, por tales circunstancias, está sometido a la voluntariedad y privacidad de las partes, son estas las razones por las cuales muchas personas o empresas escogen este mecanismo alterno de solución de conflictos que genera celeridad.

\section{Asuntos sometidos a arbitraje en Colombia}

Ahora, según el Ministerio del Interior y Justicia, cuando se habla de la conciliación civil también se engloba la comercial, involucrando conflictos de naturaleza patrimonial, en todas las esferas del derecho, aconteciendo lo mismo con el arbitraje (MinInterior, 2021), entre los señalados conflictos que pueden someterse a la justicia arbitral se encuentran los conflictos estatales, los internacionales, contratos que involucran la prestación de un servicio público, los laborales, entre otros, los cuales son sometidos por regla general a arbitrajes técnicos, pues requieren de un conocimiento especializado sobre determinado asunto (Cristancho, 2002). No obstante lo antes dicho, es importante indicar que en esta oportunidad miraremos los casos en los cuales los asuntos pueden ser atendidos ante Tribunal de Arbitramento, encontrándose los siguientes:

1. Cuando se debatan conflictos atinentes a contratos de arrendamiento, según la Ley 446 (1998, art. 1141), no obstante, implican además de los incumplimientos alegados por las partes, su terminación y el régimen sobre su existencia. Sin embargo, para adelantar ejecuciones por laudos en estos conflictos, se deberá adelantar ante la jurisdicción ordinaria con sus procedimientos y tramites. 
2. Procesos especiales en materia laboral colectiva, es decir, aquellos que estuvieron sujetos a conflicto colectivo, y una vez se decidió resolverse por este medio y/o en su defecto lo escogieron de manera voluntaria $u$ obligatoria, tienen un tramite especial de igual manera que los demás sometidos a arbitraje.

3. Los procesos ejecutivos, pues de acuerdo con la Sentencia T-299 (1996), acompasado con el artículo constitucional 116 (CP, 1991), pueden ser habilitados los árbitros, siempre y cuando la razón del proceso ejecutivo naciere en un fallo arbitral, no obstante, según García (2013), al no existir normas legales que estructuren o dejen en claro cómo se tramitaría tal proceso, no se aplica aún el mismo.

4. Arbitraje empresarial o comercial, el cual se desarrolla entre socios dentro de una empresa, siendo un tipo de arbitraje especial, y este puede usarse cuando las partes hacen un pacto para acudir al Centro de Conciliación y Arbitraje Empresarial de la Superintendencia de Sociedades y sumado a ello están de acuerdo en acoger el reglamento especial (Barona, 2007).

El procedimiento consiste en que la parte legitimada en la causa por activa por el incumplimiento presenta su acción ante el Centro de Conciliación y Arbitraje Empresarial, con todas y cada una de las pruebas necesarias para su desarrollo, anotando en consecuencia, una reseña de los acontecimientos, el poder del abogado que le representa, así como las direcciones sonde podría ser debidamente notificado. Este Proceso sólo tiene un término de 90 días para el procedimiento de la respectiva decisión, y puede incrementarse sólo por 30 días, el procedimiento incluye audiencia de instalación en donde se verifica si es admitida o no la demanda, posteriormente se fija fecha para la primera audiencia en donde el llamado contesta la demanda, creándose el calendario del proceso, que es como unas etapas a las cuales de manera consecuencial se les fija la debida fecha, así entonces los árbitros pueden solicitar y entregársele las pruebas correspondientes. 
Así entonces, es importante indicar que el arbitraje en verdad es una herramienta relevante en Colombia, motivo por el cual, se reitera la importancia de esta investigación documental al respecto, y así seguir soportando la importancia de tener conocimiento sobre los diferentes asuntos que tocan la órbita de su necesidad. Sin embargo, Rey (2013) hace énfasis en que las problemáticas que la aquejan se resumen en los excesivos formalismos, el valor económico que se cobra por los mismos, la poca gama de servicios en las diferentes ciudades del país, y el desconocimiento. Precisamente sobre el valor de los honorarios que se causan después del procedimiento del laudo arbitral, se tiene como el mayor inconveniente para acceder al arbitraje, esto previa votación de la decisión por parte de los respectivos árbitros, sobre la decisión a tomarse o cuando ya se encuentre en firme el laudo arbitral, cobrándose por honorarios los límites de sumas de SMLMV de la siguiente manera:

TABLA 1.

Cobro de Honorarios.

\begin{tabular}{lll}
\hline \multicolumn{1}{c}{ Cuantía del Proceso } & \multicolumn{1}{c}{ Honorarios por arbitro } & \multicolumn{1}{c}{ Secretario } \\
\hline Menos de 10 smmlv & $\begin{array}{l}\text { 10 salarios mínimos diarios } \\
\text { legales vigentes (SMDLV) }\end{array}$ & 5 SMDLV \\
Entre 10 y hasta $176 \mathrm{smmlv}$ & $3.25 \%$ & $1.6 \%$ \\
Más de 176 e igual a $529 \mathrm{smmlv}$ & $2.25 \%$ & $1.1 \%$ \\
Más de 529 e igual a $882 \mathrm{smmlv}$ & $2 \%$ & $1 \%$ \\
Más de 882 e igual a $1764 \mathrm{smmlv}$ & $1.75 \%$ & $0.875 \%$ \\
Mayor a 1764 & $1.5 \%$ & $0.75 \%$ \\
\hline
\end{tabular}

Fuente: Elaboración propia a partir de SuperSociedades (2019).

De lo anterior es claro que, el arbitraje de las Cámaras de Comercio, es bueno en el entendido de ahorro en instalaciones y, secretaria de Tribunales conformados de manera provisional, además máximo podrá durar 120 días, por ello se creó la figura del calendario procesal que permite que se evacue con mayor diligencia durante las diferentes etapas del proceso, no siendo la conciliación requisito de procedibilidad (Supersociedades, 2019). Ahora, como se dijo en el 
acápite atinente a los asuntos sujetos a arbitraje en Colombia, se tiene que en derecho laboral, también se observa en donde hay dos tipos de arbitramento uno obligatorio y el otro voluntario, no obstante, por esta especialidad pueden ser de carácter voluntario, tanto asuntos de derecho laboral individual como colectivo, no obstante, siempre estará condicionado a que, la cláusula compromisoria, se encuentre depositada en un pacto o convención colectiva, mientras que, de carácter obligatorio, aquellos que trae el Código Sustantivo del Trabajo (1950, art. 430), cuando dice:

1. Los que involucren servicios públicos esenciales.

2. Los conflictos laborales que de manera voluntaria el sindicato haya escogido ir a Tribunal de Arbitramento.

3. Aquellos conflictos colectivos de sindicatos conformados por la tercera parte o menos del total de los trabajadores de la empresa, y de manera conjunta hayan decidido ir a Tribunal de Arbitramento.

4. Cuando agotada la huelga no hayan logrado llegar a acuerdos (González, 2008).

Ahora, en cuanto al procedimiento que debe seguirse para el arbitramento en materia laboral, se tiene que la parte que este legitimada para invocarlo en este caso el sindicato elevar tal petición ante el Ministerio del Trabajo, quien debe estudiar que se cumplan con los requisitos de procedibilidad y, así proceder a convocar al Tribunal de acuerdo con la lista disponible de árbitros en ese departamento, en este caso son seleccionados tres árbitros, los cuales es recomendable que se escoja uno por cada una de las partes, y si llegarén a tener dificultades sobre el tercero, pues deberá el MinTrabajo escoger de la lista disponible que manera previa convocatoria pública la Corte Suprema de Justicia en su Sala de Casación Laboral, a quien se les deberá notificar si aceptan o no dichas funciones (Sentencia C-538, 2016).

Es importante decir, que a continuación transcurridos los diez (10) días luego de la designación correspondiente de los árbitros, estos deberán dictar el fallo arbitral sobre el asunto que les corres- 
pondiere, con la valoración probatoria y, análisis pertinente del asunto, siendo susceptible del recurso de anulación si alguna de las partes involucradas considera interponerlos.

\section{Eficacia del Arbitraje en Colombia}

Para tratar esta última parte de los objetivos específicos previamente planteados, se hablará de los primeros dos títulos de este trabajo, generando a partir de la pesquisa de los mismos, una apreciación crítica, que toque a fondo la necesidad de vislumbrar cuales son las razones fundamentales por las cuales es importancia y eficaz el proceso arbitral en Colombia. Es importante anotar, que, tratándose de este proceso, se generán dudas en si en verdad es netamente arbitraje o por el contrario no es más que un proceso judicial de carácter especial, pues al observarse cada uno de los casos en los que puede operar, es importante anotar que cada uno de ellos posee unas etapas muy semejantes, pero que sirven de gran relevancia a la hora de emitirse el fallo (Rodríguez, 2012). Según el Centro de Arbitraje y Conciliación de la Cámara de Comercio de Bogotá (s.f):

Desde 2012 hasta el 30 de junio de 2018, el Centro de Arbitraje y Conciliación ha radicado cerca de 2.191 demandas de arbitraje (nacional: 2155 e internacional: 36 ).

Contamos con las listas de árbitros y secretarios más completas y especializadas en el país. En la actualidad, tenemos 644 árbitros y 132 secretarios inscritos.

Desde enero de 2012 a junio de 2018 se han proferido 602 laudos de arbitraje nacional (párr. 1-3).

De acuerdo a la revista Semana (2016), "para evitar largos procesos judiciales y reducir costos en demandas, empresas e instituciones recurren cada vez más al arbitraje" (párr. 1), figura que se ha convertido en uno de los sectores de negocio más importantes de la abogacía: 
Ha sido tan exitosa esta figura durante 2015, que en el Centro de Arbitraje de la Cámara de Comercio de Bogotá (CCB) fueron radicadas 293 demandas, de las cuales $27 \%$ conciernen a conflictos donde una de las partes es una entidad pública (derecho administrativo), $46 \%$ a negocios (derecho comercial), 23\% a tópicos distintos a lo comercial (derecho civil) y $4 \%$ a controversias de otras especialidades jurídicas. El valor de las pretensiones por demandas arbitrales tramitadas en la Cámara de Comercio de Bogotá alcanzó $\$ 2,42$ billones y en el primer semestre de este año llegó a \$1,11 billones (Semana, 2016, párr. 4).

Asi entonces, frente a lo desarrollado es relevante anotar cuáles son esos aspectos positivos del arbitraje que se convierten en razones valederas, para aseverar que es eficaz, y de cara a ello lo primero que hay que decir, es que solo esta limitado a un sector de la población en general que quiere librar las diferencias, y que por ello observan las siguientes razones:

1. Quienes acuden a este mecanismo alterno de solución de conflictos, lo hacen con la convicción de en verdad resolver la problemática, pues hay un compromiso desde el inició, de concertirse esta en la mejor opción para su conflicto, lo cual os indica que por regla genaaral quienes acceden a someter sus diferencias, son personas que cuentan con un convencimento de ser la mejor opción y/o la unica.

2. Pagar más en realidad se convierte en pagar menor, pues si bien hay que cubrir unos honorarios, es peor que el proceso se acrecente o sea sometido a otra jurisdicción donde puede tardar años en ver luces de desiciones, mientras las moras van aumentando y las clausulas y asperezas continuan en el ambiente, es por ello, que es fundamental el compromiso de acudir con la seguridad de tener una respuesta especializada.

3. Desición neutral, pues los árbitros que deciden el asunto, son escogidos por ambas partes, y ambos en verdad deben pagarlos, es por ello que resulta trascendental que desde el principio deben acordar los pasos a seguir, teniendo hasta una visión de las posibilidades que han de suceder, desembocando este aspecto en seguridad y tranquilidad para todos y cada uno de los involucrados. 
4. Solución rapida y avalada por un árbitro experto, que en un tiempo más que prudencial, los ubicara en el paso a seguir, quedando en la mayoria de los casos, en el pasado el asunto, pero guardando como experiencia el caso vivido, mejorando así la calidad en el manejo de las instituciones, reflejandose en quienes la conozcan.

5. Concienciar a las personas en que los mecanismos alternos estan allí para ayudarnos a crecer y no enfrascarnos en las problematicas, a través de avances significativos que beneficien a ambas partes, frente a los MASC el egísmo quedaria detrás para centrarnos en una solución conjunta en que a pesar de las entregas materiales, nos quedemos en paz, aunque es lo más dificil.

6. Concreta en una replica de acciones estructurada, que lleva a la aplicación de prevención a nivel empresarial, pues de cara a la enseñanza que deja el haber liderado un proceso arbitral como una de las partes, implementaran estrategias que busquen evitar malos negocios, verbigracia incumplimientos o duden en el momento que corresponda.

7. Crea cargos para muchaspersonas que se enfoquen en el area de metodos alternos e solución de conflictos como por ejemplo en consultorios juridicos de universidades o independientes, camaras de comercios, tribunales temporales, convocatorias de las altas cortes, y muchos otros empleos enfocados a la salvaguarda de las victimas del conflicto armado en busca de la paz, como organizaciones internacionales. Pues al ser un area general no tiene exclusión al momento de participar.

8. Reducción de congestión judicial, un mal que aqueja la administración de justicia, pero que logra con retraso su cometido, este beneficio que brinda el arbitraje, queda sostenido hasta la fecha para población empresarial, por lo que se podría afirmar que en los despachos judiciales son pocos los asuntos sometidos a jurisdicción ordinaria, sobre este tema, liderando la bandera el arbitraje.

9. La necesidad de extender el beneficio del arbitraje en los diferentes escenarios, pero bajo gratuidad, es decir, que el Estado ubique a posibilidad de arbitros bajo el pago de honorarios menos gravosos que los actuales, lo que llevaria a que la figura se propague de manera considerable en el territorio colombiano. 
10. El reconocimiento internacional como un país que ha luchado por implementar los mecanismos alternos de solución de conflictos a su medio y su realidad, a traves por ejemplo del proceso de paz, y que pese a la corrupićn sigue luchando desde cada rincon por lograr una justicia social efectiva (Centro de Estudios de Justicia de las Américas-CEJA, 2016).

\section{Conclusiones}

Se puede afirmar que en Colombia se evidencia la existencia de arbitrajes de todo tipo, es decir, en todas las áreas del Derecho, tanto en materia laboral (muy pocos) ya no son procedentes, como civil, comercial, administrativos, comercial y contratación estatal, sin embargo; es evidente que no solo se debe ver lo oneroso de su utilización, pues es claro que tiene muchísimo que brindar, siendo uno de los que mayores beneficios posee en tratándose de una justicia alternativa, pese a no ser muy utilizado, por tal razón se deberían tomar medidas para que su inclusión sea más amplia. Es importante resaltar de igual manera, que hay arbitramentos voluntarios y otros obligatorios, ambos poseen unos presupuestos algo diferentes, pero no totalmente excluyentes, lo que ayuda de manera considerable a su apoyo entre diferentes ramas, apuntándole a una descongestión judicial eficiente.

Sin embargo, este trabajo se diferencia por aportar a la comunidad académica y no académica, el poder observar como el arbitraje es en verdad eficaz, y esto se logra con una profusa labor pedagógica, la cual permita a los usuarios de la justicia comprender su esencia, su trámite, los sujetos que más acceden a ella, los resultados obtenidos, obteniéndose poco a poco una metamorfosis mental de las personas para comprender que es mejor comprender la favorabilidad de una justicia preventiva más que restaurativa y lamentable y por tanto más extensa. Así las cosas, el arbitraje es beneficioso para la nación colombiana, y tiene fuertes bases para seguir avanzando, pues pese a lo cuantioso, puede convertirse en una herramienta más efectiva que la justicia ordinaria congestionaste de estos tiempos. 


\section{REFERENCIAS}

Alzate, R. (2011). Teoría del conflicto. Madrid: Universidad Complutense de Madrid.

Corporación Nuevo Arcoiris. (2003). Conflicto y cultura de paz. Camino de Desarrollo y paz - Mediación del conflicto. Bogotá, D.C.: Corporación Nuevo Arcoiris. Recuperado de http:// www.psicosocial.net/historico/index.php?option=com docman\&view $=$ download\&alias $=489$-conflicto-y-culturade-paz\&category_slug=resolucion-de-conflictos-inv-parapaz\&Itemid $=100225$

Barona, S. (2007). Arbitraje y Justicia en el Siglo XXI. Pamplona: Thomson Civitas.

Cabana-Grajales, M. (2017). De los mecanismos alternativos de solucion de conflictos en Colombia: acerca de su alcance y desarrollo para su implementación en los municipios de Post-Conflicto. [Trabajo de grado]. Bogotá, D.C.: Universidad Catolica de Colombia. Disponible en http://hdl.handle. net/10983/14606

Caicedo, L., Vilalobos, S. y Murgas, I. (2014). Análisis del conflicto laboral colectivo y sus mecanismos de solución. Bogotá, D.C.: Universidad Sergio Arboleda. Recuperado de https://repository.usergioarboleda.edu.co/bitstream/handle/11232/982/analisis\%20del\%20conflicto\%20laboral\%20 colectivo.pdf?sequence $=3 \&$ isAllowed $=\mathrm{y}$

Cámara de Comercio de Bogotá. Centro de Arbitraje y Conciliación. (s.f.). Cifras y resultados. [Online]. Disponible en https:// www.centroarbitrajeconciliacion.com/Servicios/ArbitrajeNacional/Como-radicar-una-demanda-de-arbitraje/Ventajas-del-Arbitraje/Cifras-y-resultados (Consultado en 2019)

CEJA. (2016). Mecanismos alternativos de resolución de conflictos.

Sistemas Judiciales, 16(20). Recuperado de https://inecip. org/wp-content/uploads/Sistemas-20-web-14-marzo-2017. pdf 
Cifuentes, F. S. (2018). El Arbitraje Juridico en Colombia. [Online]. Disponible en https://www.acj.org.co/images/descargas/trabajos_academicos/El-Arbitraje-Juridico-en-Colombia.pdf (consultado el 28 de agosto de 2018)

Cristancho, J. P. (2002). La Conciliación y Mecanismos Alternativos de Solución de Conflictos. Bogotá, D.C.: Ediciones Libreria del Profesional.

Cristóbal, S. (2013). Sistemas alternativos de resolución de conflictos: negociación, conciliación, mediación, arbitraje, en el ambito civil y mercantil. Anuario Jurídico y Económico Escurialense, (46), 39-62. Disponible en https://dialnet. unirioja.es/servlet/articulo?codigo $=4182033$

Fuquen, M. E. (2003). Los conflictos y las formas alternativas de resolución. Tabula Rasa, 3-15. Recuperado de http://www. revistatabularasa.org/numero-1/Mfuquen.pdf

Galicia, F. (2016). Los Mecanismos Alternativos de Solución de Conflictos y las Victimas en el proceso penal acusatorio. En, P. González, J, Witker y C. Natarén (Coord.), Las Victimas en el sistema penal acusatorio (pp. 55-63). México, D.F.: USAID. Recuperado de https://archivos.juridicas.unam. $\mathrm{mx} / \mathrm{www} / \mathrm{bjv} / \mathrm{libros} / 9 / 4258 / 7 . p d f$

García, F. S. (2013). La conciliación Civil y Comercial. Bogotá, D.C.: Ibañez.

Gil, J. H. (2011). La Conciliación Extrajudicial y la Amigable Composición. [2 Ed.]. Bogotá, D.C.: Temis.

Gil, J. (1989). Nuevo regimen de arbitramiento. Bogotá, D.C.: Cámara de Comercio de Bogotá. Disponible en http://hdl.handle. net/11520/21149

González, F. (2008). La naturaleza jurídica del arbitraje. Un ejercicio de balance químico. Anuario Mexicano de Derecho Internacional, 8(1), 509-525. http://dx.doi.org/10.22201/ iij.24487872e.2008.8.251 
Junco, J. R. (2007). La conciliación, aspectos sustanciales y procesales y en el sistema acusatorio. Bogotá, D.C.: Jurídica Radar y Temis.

Manzano, M. y Torres, C. (2000). La negociación como una alternativa en la solución de conflictos. [Trabajo grado]. Pontificia Universidad Javeriana, Bogotá, D.C., Colombia. Disponible en http://148.202.167.116:8080/jspui/bitstream/123456789/3208/1/La\%20negociaci\%C3\%B3n\%20 una $\% 20$ alternativa\%20en\%20la\%20soluci\%C3\%B3n\%20 de\%20conflictos.pdf

Montes, A. (2018). Mecanismos Alternativos de Solución de Conflictos. LUMEN, Revista de la Facultad de Derecho de la Universidad Femenina del Sagrado Corazón, , 115-116. Recuperado de https://revistas.unife.edu.pe/index.php/lumen/article/view/512

Narváez, B. y Osorio, P. (2019). Características y perspectivas de la transitoriedad del arbitraje nacional colombiano como mecanismo alternativo de solución de conflictos a la luz de la ley 1563 de 2012. En, B. Narváes y J. Valdelamar (eds.), Acceso a la justicia y construcción de paz. Aportes y discusiones desde el Consultorio Jurídico y Centro de Conciliación de CECAR, años 2016-2018 (pp. 260-282). Sincelejo: CECAR. https://doi.org/10.21892/978-958-5547-80-3.10

Peláez, R. A. (2017). Los Mecanismos Alternativos de Solución de Conflictos. Revista Misión Jurídica, 10(13), 279-303. Recuperado de https://www.revistamisionjuridica.com/wpcontent/uploads/2020/09/12-Los-mecanismos-alternos-desolucion-de-conflictos.pdf

Pérez, J. (2015). Cultura de paz y resolución de conflictos: la importancia de la mediación en la construcción de un estado de paz. Ra Ximhai, 11(1), 110-111. Disponible en http://www. revistas.unam.mx/index.php/rxm/article/view/71154

RAE. (s.f.). Conflicto. [Online]. Disponible en https://dle.rae.es/conflicto 
República de Colombia. Asamblea Nacional Constituyente. (1991). [Constitución Política de Colombia]. Gaceta constitucional, 1(114). Disponible en https://babel.banrepcultural.org/digital/collection/p17054coll26/id/3743/

República de Colombia. Congreso de la República. (12 de julio de 2012). Por medio de la se expide el estatuto de Arbitraje Nacional e Internacional y se dictan otras disposiciones. [Ley 1563]. DO: 48489. Disponible en http://www.secretariasenado.gov.co/senado/basedoc/ley_1563_2012.html

República de Colombia. Congreso de la República. (5 de enero de 2001). Por la cual se modifican normas relativas a la conciliación y se dictan otras disposiciones. [Ley 640]. DO: 44303. Recuperado de https://www.oas.org/dil/esp/ Ley_640_de_2001_Colombia.pdf

República de Colombia. Congreso de la República. (8 de julio de 1998). Por la cual se adoptan como legislación permanente algunas normas del Decreot 2651 de 1991, se modifican algunas del Código de Procedimiento Civil, se derogan otras de la Ley 23 de 1991 y del Decreto 2279 de 1989, se modifican y se expiden normas del Código Conternsionso Administrativo y se dictan otras disposiciones sobre descongestión, eficiencia y acceso a la justicia. [Ley 446]. DO: 43335. Disponible en https://www.oas.org/dil/esp/ley_446_ de_1998_colombia.pdf

República de Colombia. Congreso de la República. (7 de septiembre de 1998). Por medio del cual se expide el Estatuto de los mecanismos alternativos de solución de conflictos. [Decreto 1818]. DO: 43380. Disponible en https://www.funcionpublica.gov.co/eva/gestornormativo/norma.php?i=6668

República de Colombia. Congreso de la República. (28 de octubre de 1993). Por la cual se expide el Estatuto General de Contratación de la Administración Pública. [Ley 80]. DO: 41094. Disponible en http://www.secretariasenado.gov.co/senado/ basedoc/ley_0080_1993.html 
República de Colombia. Congreso de la República. (21 de marzo de 1991). Por medio de la cual se crean mecanismos para descongestionar los despachos judiciales y se dictan otras disposiciones. [Ley 23]. DO: 39752. Disponible en https:// www.funcionpublica.gov.co/eva/gestornormativo/norma. php?i $=6546$

República de Colombia. Congreso de la República. (7 de octubre de 1989). Por la cual se implementan sistems de solución de conflictos entre particularidades y se dicta otras disposiciones. [Decreto 2279]. DO: 39012. Disponible en https:// www.funcionpublica.gov.co/eva/gestornormativo/norma. php?i=77501

República de Colombia. Corte Constitucional. (5 de octubre de 2016). Expediente D-11287. [Sentencia C-538]. Magistrado Ponente: Luis Ernesto Vargas Silva. Disponible en https:// www.corteconstitucional.gov.co/relatoria/2016/C-538-16. htm

República de Colombia. Corte Constitucional. (8 de julio de 1996). Expediente T-87.302. [Sentencia T-299]. MP: Vladimiro Naranjo Mesa. Disponible en https://www.corteconstitucional.gov.co/relatoria/1996/T-299-96.htm

República de Colombia. MinInterior. (2021). Guía Institucional de Conciliación en Comercial. Bogotá, D.C.: MinInterior. Recuperado de https://www.udea.edu.co/wps/wcm/ connect/udea/9870ef26-3e50-46fb-b893-b1d10f64350c/ GuiaInstitucionalDeConciliacionComercial_MinJusticia. pdf?MOD=AJPERES

República de Colombia. Presidencia de la República. (20 de diciembre de 1950). Por el cual se modifica el Decreto número 2663 de 1950, sobre Código Sustantivo del Trabajo. [Código Sustantivo del Trabajo]. DO: 27622. Disponible en http:// www.secretariasenado.gov.co/senado/basedoc/codigo_sustantivo_trabajo.html 
Rey, P. (2013). El arbitraje y los ordenamientos juridicos en latinoamerica. Un estudio sobre Formación y Judicialización. Vniversitas, 62(126), 199-237. Disponible en https://revistas. javeriana.edu.co/index.php/vnijuri/article/view/6125

Rodríguez, M. (2012). Una aproximación al régimen del arbitraje nacional del nuevo estatuto del arbitraje en Colombia, Ley 1563 de 2012. Revista de Derecho Privado, (23), 367-405. Disponible en https://revistas.uexternado.edu.co/index.php/ derpri/article/view/3312

Semana. (julio 20, 2016). ¿Por qué los tribunales de arbitraje recogen cifras millonarias? Semana. Disponile en https://www.semana.com/edicion-impresa/caratula/articulo/por-que-lostribunales-de-arbitraje-recogen-cifras-millonarias/225894/

Supersociedades. (2019). Conceptos jurídicos emitidos por la superintendencia de sociedades. [Boletín]. Recuperado de https:// www.supersociedades.gov.co/documentos\%20compartidos/2019/conceptos_juridicos_04.pdf

Articulo resultado de investigación del proyecto de convocatoria interna de CECAR, titulado: Modelo integrador de construcción de paz desde la familia, la educación y la empresa para la reconciliación y el ejercicio de los derechos humanos en el departamento de Sucre, Colombia

Berónica Narváez Mercado es Doctorante en Derecho de la Universidad Libre de Colombia. MBA de la Escuela Libre de Derecho de Costa Rica. Abogada, Conciliadora y Docente Investigadora. Directora del Grupo de Investigaciones Socio jurídicas GISCER de la Facultad de Derecho y Ciencias Políticas de la Corporación Universitaria del Caribe-CECAR (Sincelejo, Colombia). http://orcid. org/0000-0003-4161-9275

Fredy Castilla Paba es Especialista en Derecho Procesal Civil y Abogado de la Corporación Universitaria del Caribe-CECAR (Sincelejo, Colombia). http://orcid.org/0000-0003-2659-361X 